\title{
Шихнабиева Э.Д.
}

\section{Клиническая эффективность применения инъекционной тромбоцитарной аутоплазмы в комплексной терапии больных хроническим пародонтитом легкой степени}

\author{
Shikhnabieva E.D. \\ Clinical efficiency of application of an injection trombotsitarny \\ autoplazma in complex therapy of patients with a chronic \\ periodontal disease of easy degree
}

Изучена клиническая эффективность применения в комплексной терапии инъекционной формы тромбоцитарной аутоплазмы у 36 больных хроническим пародонтитом легкой степени (этим больным после традиционной терапии в область зубодесневых сосочков и маргинальной десны вводилась тромбоцитарная аутоплазма). Контролем служили 20 больных, получивших только традиционную терапию. Результаты исследования (осмотр, определение глубины пародонтальных карманов, пародонтального индекса, индекса кровоточивости десны, рентгенологическое обследование) показали, что применение тромбоцитарной плазмы в комплексной терапии пародонтита легкой степени, по сравнению с традиционным методом, стабилизирует воспалительный процесс, дает более стойкий клинический эффект и способствует длительной ремиссии заболевания Ключевые слова: тромбоцитарная аутоплазма, плазмолифтинг, пародонтит

\section{Шихнабиева Эльмира Даировна}

Кандидат медицинских наук, ассистент

Дагестанский медицинский стоматологический институт

Дагестан, г. Махачкала, ул. Азиза Алиева, 25
The clinical efficacy of adjuvant therapy in injection form platelet autoplasma in 36 patients with chronic periodontitis mild (these patients after conventional therapy to periodontal papillae and marginal gingiva introduced platelet autoplasma). The control group consisted of 20 patients who received only conventional therapy. Results of the study (examination, determination of the depth of periodontal pockets, periodontal index, gingival bleeding index, roentgenologic inspection) showed that the use of platelet-plasma tare in the complex therapy of periodontitis mild, compared with the traditional method, stabilizes the inflammatory process, gives a more stable clinical effect and contributes to longterm remission of the disease

Key words: platelet autoplasma, Plazmolifting, periodontitis

\section{Shikhnabiyeva Elmira Dairovna \\ Candidate of Medical Sciences, Assistant \\ Dagestan medical stomatologic institute \\ Dagestan, Makhachkala, Aziz Aliyev st., 25}

Воспалительные заболевания пародонта представляют одну из наиболее актуальных проблем стоматологии, имеющей не только общемедицинскую, но и социальную значимость, что обусловлено высокой распространённостью, интенсивностью течения процесса, последующим формированием хрониче- 
ского одонтогенного очага инфекции, потерей зубов в молодом возрасте и неблагоприятным его влиянием на организм. По данным разных авторов, патологией пародонта страдает от 33 до 85\% населения [1, с. 26; 3, с. 3]. Такой высокий процент распространенности заболеваний свидетельствует о том, что данная патология крайне сложно поддается лечению, а устранить дальнейшее развитие заболевания практически не возможно. Это обусловлено тем, что для пародонтитов характерен комплекс патологических изменений, в основе которых лежит неуклонно прогрессирующее и волнообразно текущее хроническое воспаление, распространяющееся из десны на нижние отделы пародонта.

Сложность лечения воспалительных заболеваний пародонта заключается в том, что известные и стандартные методы (антибактериальная терапия и курсы местной терапии) не всегда дают положительный результат и длительный период ремиссии [4]. Поэтому для улучшения качества лечебной помощи пациентам с патологией пародонта необходимо внедрить в стоматологическую практику новые инновационные методы лечения [6, с. 253]. Одним из таких методов на сегодняшний день является инъекционный метод с использованием плазмы, полученной из собственной крови пациента, - тромбоцитарной аутоплазмы, получивший оригинальное название PlasmoliftingTM [2, с. 96; 5, 18 с.]. Пристальный интерес к аутоплазме прежде всего обусловлен тем, что в тромбоцитах содержатся многочисленные факторы роста и цитокины, способствующие регенерации поврежденных тканей [6, с. 253]. Благодаря этим факторам, введенная в ткани тромбоцитарная плазма, вызывает прорастание капилляров, нормализует гемодинамику, тканевое дыхание, обмен веществ. Одновременно происходит процесс укрепления костной ткани, формирование матрикса коллагена и кости с участием костных морфогенетических белков коллагена, а также активируется местный иммунитет. Применение аутоплазмы исключает возможность инфицирования и аллергических реакций.

Целью исследования явилась оценка клинической эффективности применения в комплексной терапии инъекционной формы тромбоцитарной аутоплазмы при лечении генерализованных пародонтитов легкой степени.

Материал и методы исследования. Было исследовано 56 больных генерализованным пародонтитом легкой степени с давностью заболевания до 5 лет. Из них 36 больных (19 мужчин и 17 женщин, возраст от 33 до 40 лет) составляли основную группу, 20 больных (11 мужчин и 9 женщин, возраст от 36 до 42 лет) - контрольную группу. Лечение пародонтита включало профессиональную гигиену полости рта с использованием скейлера и полировочных паст и щеток, обучение больных гигиене полости рта и ее контроль; хирургических мероприятий - закрытый кюретаж пародонтальных карманов, а также комплексная лекарственная терапия: противовоспалительный препарат «Метрогилдента-гель» в течение 7 дней 2 раза в сутки по 10 мин в виде аппликаций. На последней стадии больным основной группы, с целью улучшения процессов регенерации, проводились инъекции с использованием тромбоцитарной аутоплазмы.

Тромбоцитарную аутоплазму получали с помощью центрифуги ЕВА20 производства Andreas Hettich GmbH\&Co, Германия (регистрационное удостове- 
рение ФС №2009/04309 метод Плазмолифтинг; авторы Р.Р. Ахмеров, Р.Ф. Зарудий). Препарат вводился в область зубодесневых сосочков и маргинальной десны из расчета 0,1-0,2 мл на 3 мм2 и в область переходной складки 0,3-0,5 мл на 1-2 зуба (в общей сложности 3,5 мл плазмы на один зубочелюстной сегмент, состоящий из 6-8 зубов). Количество инъекций составило 2-3 раза в одну и ту же зону с перерывом в 7-10 дней. Время, затрачиваемое врачом на одну процедуру с использованием одной пробирки, в среднем составило 27-30 минут. Все больные отмечали хорошую переносимость препарата. Ни в одном случае не отмечалось каких-либо побочных эффектов.

Клиническое обследование включало в себя: осмотр, определение глубины пародонтальных карманов, а также пародонтального индекса (ПИ) по Russel, индекса кровоточивости десны (ИК) по H.P.Muhlemann и рентгенологическое обследование. Все индексы регистрировались в день первого посещения, после проведенного комплексного лечения до введения тромбоплазмы, после введения тромбоплазмы через 2 недели и через 3 месяца.

Результаты исследования и их обсуждение. При первичном обследовании $65 \%$ пациентов основной группы и 63,8\% пациентов группы сравнения предъявляли жалобы на кровоточивость десен, возникающие при чистке зубов. При объективном обследовании у пациентов обеих групп отмечались незначительная гиперемия и отечность десны, наличие пародонтальных карманов, кровоточивость при зондировании, мягкий зубной налет (преимущественно на язычных поверхностях фронтальных зубов нижней челюсти и на щечных поверхностях жевательных зубов верхней челюсти), минерализованные зубные отложения (соответственно у 38,9\% 1-ой и 40\% 2-ой групп). У больных обеих групп подвижность зубов была в пределах физиологической нормы, а рентгенологически определялись резорбция межальвеолярных перегородок до 1/3. Глубина пародонтального кармана до лечения у пациентов основной группы составила 2,6+0,3 мм, группы сравнения - 2,5+0,2 мм, уровень потери зубодесневого соединения - соответственно 3,6+0,3 мм, группы сравнения $3,4+0,3$ мм. Исходный уровень индекса Мюллемана в основной и контрольной группах составил соответственно 1,36+0,04 и 1,32+0,05 усл. ед., пародонтальный индекс Russela - соответственно 1,14+0,19 и 1,16+0,18 усл. ед.

После проведенного комплексного лечения заметно купировалась активность патологического процесса, что выражалось в уменьшении воспалительной реакции, индекс кровоточивости снизился достоверно $(\mathrm{P}<0,05)$ от исходных значений в обеих группах, до 1,1+0,07 усл. ед. в основной группе и до $1,13+0,04$ усл. ед. в контрольной, что соответствовало состоянию пародонта легкой степени. Динамика ПИ была следующей: после проведения профессиональной гигиены и комплексного лечения он снизился достоверно в обеих группах, до 0,78+0,05 усл. ед. в основной группе и до 0,75+0,09 усл. ед. в контрольной группе.

Клиническая картина через 2 недели после плазмодента в контрольной группе существенно не изменилась, а в основной группе наблюдалась полная нормализация состояния тканей пародонта: десна бледно-розового цвета, плотно охватывала шейки зубов, безболезненна, подвижность зубов значи- 
тельно уменьшилась или отсутствовала вовсе. Отмечалось более выраженное снижение показателя кровоточивости в основной группе до 0,54+0,12 усл.ед., а через 3 месяца до 0,12+0,05 усл. ед., в контрольной группе показатель кровоточивости через 2 недели также снизился, но не так выражено, как в основной группе, до 0,92+0,23 усл. ед., затем через 3 месяца оставался на том же уровне $0,93+0,21$ усл. ед.

После плазмодента через 2 недели индекс ПИ в основной группе снизился до 0,53+0,06 усл. ед. и особо не изменился в контрольной группе - 0,72+0,04 усл. ед. В динамике через 3 месяца индекс ПИ в основной группе снизился более выраженно и достоверно - 0,41+0,04 усл. ед., в контрольной группе значительно не изменился и составил 0,69+0,06 усл. ед. В основной группе наблюдалась стойкая стабилизация процесса в 74,6\% случаев.

Таким образом, клинические показатели и оценка пародонтальных индексов подтверждают терапевтический эффект применения тромбоцитарной аутоплазмы в комплексном лечении больных с хроническим генерализованным пародонтитом легкой степени.

Вывод. Применение тромбоцитарной аутоплазмы в комплексной терапии пародонтита легкой степени, по сравнению с традиционным методом, стабилизирует воспалительный процесс, дает более стойкий клинический эффект и способствует длительной ремиссии заболевания. Данный метод является перспективным направлением в терапевтической стоматологии и требует дальнейшего развития и углубленного научного исследования.

\section{Список используемых источников:}

1. Аболмасов Н.Г. Современные представления и размышления о комплексном лечении заболеваний пародонта // Российский стоматологический журнал. 2009. № 5. С. 26.

2. Ахмеров Р.Р., Короткова О.И., Овечкина М.В., Зарудий Р.Ф., Воробьев А.А. Применение аутоплазмы, содержащей тромбоциты, в дерматокосметологии и стоматологии // Пластическая хирургия и косметология. 2013. № 1. С. 96.

3. Горбачева И.А. Связь заболеваний внутренних органов и полости рта // Пародонтология. 2009. № 3 (52). C. 3.

4. Карданова Л.В., Тхазаплижева М.Т., Балкаров А.О. Некоторые аспекты местного лечения хронических воспалительных заболеваний пародонта // Современные проблемы науки и образования. 2014. № 6 .

URL: www.science-education.ru/120-15777

5. Махмутова А.Ф. Эффективность комплексного восстановительного лечения больных воспалительными заболеваниями пародонта: Автореф. дисс.... канд. мед. наук. М., 2009. С. 18. 6. Таранова Н.Ю., Виниченко Е.Л., Перова Н.Ю., Борискова И.В. Плазмолифтинг как инновационный метод лечения заболеваний пародонта на этапе послевузовского обучения // Международный журнал экспериментального образования. 2014. №4. С. 253-255.

(C) 2015, Шихнабиева Э.Д.

Клиническая эффективность применения инъекционной тромбоцитарной аутоплазмы в комплексной терапии больных хроническим пародонтитом легкой степени
(C) 2015, Shikhnabieva E.D.

Clinical efficiency of application of an injection trombotsitarny autoplazma in complex therapy of patients with a chronic periodontal disease of easy degree 